\title{
Implementasi Standar Prasarana di SMAN Se-Kecamatan Koto Tangah Padang
}

Ridha Nabila 1, Syahril 2, Ahmad Sabandi 3, Yulianto Santoso 4

1,2,3,4 Administrasi Pendidikan, Universitas Negeri Padang

Ridha Nabila ${ }^{1}$, e-mail: ridhanabila02@yahoo.co.id

Syahril², e-mail: syahril@ fip.unp.ac.id

Ahmad Sabandi³, e-mail: sabandi@fip.unp.ac.id

Yulianto Santoso ${ }^{4}$, e-mail: yuliantosantoso@fip.unp.ac.id

\begin{abstract}
This study aims to describe the suitability of existing infrastructure in schools with predetermined standards. This research is a descriptive study with qualitative methods. Data werecollected using interview, observation (observation) and documentation study. Data analysis using interactive analysis techniques include data reduction, data presentation and drawing conclusions. For data validity using triangulation technique. The result stated that (1) sman classroom $(7,8,13)$ Padang were appropriate, (2) sman library room $(7,8,13)$ field is very suitable, $(3)$ sman biology laboratory room $(7,8,13)$ field is very suitable, (4) the physics laboratory room of SMAN $(7,8,13)$ the field is very suitable, $(5)$ the chemistry laboratory room of SMAN $(7,8,13)$ the field is very suitable, $(6)$ the computer laboratory room of SMAN $(7,8,13)$ the field is very suitable, $(7)$ the laboratory room of sman language $(7,8,13)$ the field is not suitable, (8) sman leadership room $(7,8,13)$ field is very suitable, $(9)$ sman teacher room $(7,8)$ appropriate field, SMAN 13 field is not suitable, (10) SMAN administration room $(7,8,13)$ field is very suitable, $(11)$ THE place of worship of SMAN $(7,8,13)$ of the field is very suitable, (12) the counseling room of SMAN $(7,8,13)$ of the field is very suitable, $(13)$ the uks sman room $(7,8,13)$ the field is very suitable , (14) the student organization room of SMAN 13 padang is very suitable, SMAN $(7,8)$ field is not suitable, $(15)$ latrine / toilet SMAN $(7,8,13)$ appropriate field, (16) SMAN warehouse 13 fields are very suitable, SMAN 8 appropriate fields, SMAN 7 fields are not suitable, (17) circulation space $\operatorname{SMAN}(7,8,13)$ appropriate fields, (18) playgrounds / sports SMAN 13 fields are very suitable, SMAN (7.8) fields in accordance with the infrastructure standards set out in PermendiknasNumber 24 of 2007.
\end{abstract}

\begin{abstract}
Abstrak
Penelitian ini bertujuan untuk mendeskripsikan kesesuaian prasarana yang ada di sekolah dengan standar yang telah ditetapkan. Penelitian ini merupakan penelitian deskriptif dengan metode kualitatif. Pengumpulan data dilakukandengan wawancara, observasi (pengamatan) dan studi dokumentasi. Analisis data menggunakan teknik analisis interaktif yang meliputi reduksi data, penyajian data dan penarikan kesimpulan. Untuk keabsahan data menggunakan teknik triangulasi. Hasilnya menyatakan bahwa (1) ruang kelas SMAN $(7,8,13)$ Padang sesuai, $(2)$ ruang perpustakaan $\operatorname{SMAN}(7,8,13)$ padang sangat sesuai, (3) ruang laboratorium biologi SMAN $(7,8,13)$ padang sangat sesuai, (4) ruang laboratorium fisika $\operatorname{SMAN}(7,8,13)$ padang sangat sesuai, (5) ruang laboratorium kimia $\operatorname{SMAN}(7,8,13)$ padang sangat sesuai, (6) ruang laboratorium komputer SMAN $(7,8,13)$ padang sangat sesuai, $(7)$ ruang laboratorium bahasa SMAN $(7,8,13)$ padang tidak sesuai, (8) ruang pimpinan SMAN $(7,8,13)$ padang sangat sesuai, $(9)$ ruang guru SMAN $(7,8)$ padang sesuai, SMAN 13 padang kurang sesuai, $(10)$ ruang tata usaha SMAN $(7,8,13)$ padang sangat sesuai, (11) tempat beribadah SMAN $(7,8,13)$ padang sangat sesuai, (12) ruang konseling SMAN $(7,8,13)$ padang sangat sesuai, $(13)$ ruang UKS SMAN $(7,8,13)$ padang sangat sesuai, $(14)$ ruang organisasi kesiswaan SMAN 13 padang sangat sesuai, SMAN $(7,8)$ padang tidak sesuai, (15) jamban/toilet SMAN $(7,8,13)$ padang sesuai, (16) gudang SMAN 13 padang sangat sesuai, SMAN 8 padang sesuai, SMAN 7 padang kurang sesuai, $(17)$ ruang sirkulasi SMAN $(7,8,13)$ padang sesuai, $(18)$ tempat bermain/berolahraga SMAN 13 padang sangat sesuai, $\operatorname{SMAN}(7,8)$ padang sesuai dengan standar prasarana yang telah ditetapkan dalam Permendiknas Nomor 24 Tahun 2007.
\end{abstract}

Kata Kunci:Standar Prasarana, Sekolah Menengah AtasNegeri 
How to Cite: Nabila, Ridha 1, Syahril 2. Sabandi, Ahmad 3, Santoso, Yulianto 4 2021. Implementasi Standar Prasarana di SMAN Se-Kecamatan Koto Tangah Padang. Journal Educational Administration and Leadership, Vol (N): pp. XX-XX, DOI:10.24036/XXXXXXXXXX-X-XX

This is an open access article distributed under the Creative Commons 4.0 Attribution License, which permits unrestricted use, distribution, and reproduction in any medium, provided the original work is properly cited. @2020 by author.

\section{Pendahuluan}

Pendidikan merupakan faktor penentu agar dapat meningkatkan SDM. Pendidikan mengupayakan kehidupan manusia kearah yang lebih baik pada saat yang akan datang. Untuk meningkatkan mutu pendidikan, pemerintahan Indonesia sudah melakukan perbaikan pada sistem pendidikan, baik tingkat SD, SMP, SMA dan perguruan Tinggi.

Dalam (UU RI, NO.20, 2003)menjelaskan Pendidikan yaitu usaha yang terencana dalam terwujudnya suasana belajar serta proses pembelajaran supaya siswa dapat meningkatkan kemampuan diri untuk memiliki keahlian dalam spiritual keagamaan, pengendalian diri, kepribadian, kecerdasan, akhlak mulia, serta keterampilan yang diperlukan dirinya, masyarakat, bangsa dan negara.

Di kehidupan saat ini yang selalu berkembang sejalan dengan ruang dan waktu menuntut pendidikan yang bermutu. Pendidikan bermutu bisa menjawab tantangan perubahan yang mampu membawa perubahan di bermacam dimensi kehidupan. Kemajuan untuk mengelola pendidikan merupakan indikator kemampuan juga komitmen dalam negara untuk menaikkanmutu SDM. Maka sebab itu, pengelolaan pendidikan efektif dan efisien harus menjadi komitmen bersama untuk meningkatkan kualitas pendidikan.

Sarana dan Prasarana sangatlah dibutuhkan sehingga menjadikan pendidikan yang lebih baik sertaadanya fasilitasyang memadai akan berpengaruh pada pendidikan, baik itu langsung maupun tidak langsung.Gedung, ruang belajar/kelas, alat-alat/media pendidikan, meja, kursi dan lainnya merupakan sarana dan prasarana langsung di sebuah pendidikan, begitupun sarana dan prasarana yang tidak langsung seperti halaman, kebun, taman dan jalan menuju sekolah. Sarana dan prasarana disekolah harus memenuhi standar minimum dimana tercantum pada (Permendiknas, 2007) menyatakan bahwa standar sarana dan prasarana untuk SD/MI, SMP/MTs dan SMA/MA merangkap kategori minimum sarana serta kategori minimum prasarana.

Standar sarana dan prasarana merupakan standar nasional pendidikan berkaitan dengan kategori minimal mengenai ruang kelas, tempat olahraga, tempat ibadah, perpustakaan, laboratorium, bengkel kerja, tempat bermain, tempat berkarya, dan sumber belajar yang dibutuhkan sebagai penunjang pembelajaran, termasuk teknologi dan informasi (Amtu, 2011).

Standar sarana dan prasarana sekolah dapat diartikan sebagai suatu penyesuaian bentuk, baik spesifikasi, kualitas maupun kuantitas sarana dan prasarana sekolah dengan kriteria minimum yang telah ditetapkan untuk mewujudkan transparansi dan akuntabilitas public serta meningkatkan kinerja penyelenggaraan sekolah/madrasah (M.Arifin, 2012).

Sedangkan bagian prasarana pendidikan yakni bangunan sekolah (tanah dan gedung) yang melingkupi lapangan, halaman sekolah, ruang kelas, ruang guru, kantor, ruang praktek, ruang tamu, ruang kepala sekolah, ruang perpustakaan, laboratorium, mushola, dan kamar kecil (Arikunto, 2010).

Prasarana pendidikan yaituseluruh yang tidak ada hubungan langsung dengan proses belajar mengajarseperti bangunan sekolah, ruang kelas, perpustakaan, lapangan, kebun sekolah, dan lainnya (Indarwan, 1970).

Prasarana sekolah mempunyai peranan sangat penting untuk mewujudkan terlaksananya kegiatankegiatan yang ada di sekolah, khususnya untuk kelancaran pelaksanaan proses pendidikan yang dilakukan oleh sekolah tersebut. Mencapai kesuksesan dalam beljar mengajar apabila ditunjang oleh prasarana pendidikan yang sudah memadai serta pengelolaan yang sangat baik.

Prasarana pendidikan yakni salah satu elemen yang berperan penting dalam menggapai tujuan pendidikan, karena prasarana merupakan fasilitas penunjang dalam pendidikan. 
Berdasarkan pengamatan penulis pada SMAN Se-Kec. Koto Tangah yang menjadi objek penelitian ini masih terlihat fenomena seperti :

a. Adanya ruang kelas yang belum memenuhi jumlah rombongan belajar, sehingga memanfaatkan laboratorium.

b. Masih belum adanya laboratorium bahasa di sekolah, sehingga menyulitkan siswa yang menyukai pembelajaran bahasa.

c. Ada beberapa sekolah tidak memiliki ruang organisasi kesiswaan, sehingga siswa harus berkumpul dikelas atau diruang sirkulasi saat mengadakan rapat/musyawarah.

d. Peserta didik kesulitan ketika buang air kecil/besar karena jamban/toilet sekolah tidak mencukupi sehingga peserta didik terpaksa harus antri terlebih dahulu

\section{Metode Penelitian}

Merupakanpenelitian deskriptif dengan metode kualitatif. penelitian deskriptif tersebut yaitu penelitian yang berusaha menjawab fenomena yang terjadi dilapangan dengan menggunakan langkah awal pengumpulan data, kemudian mengklasifikasikan data, melakukan analisis data, dan membuat kesimpulan terhadap data yang diperoleh serta membuat laporan dengan tujuan memberikan gambaran keadaan seobjektif mungkin (Darmadi, 2014). Key instrumens/instrumen kunci yaitu peneliti sendiri dengan instrumen bantuan dalam bentuk pedoman observasi, pedoman wawancara, dokumentasi serta alat-alat yang dibutuhkan seperti hp. Menggunakan teknik pengamatan/observasi, wawancara dan studi dokumentasi dalam pengumpulan data.

\section{Hasil Pembahasan}

Hasil dan pembahasan penelitian terkait Implementasi Standar Prasarana di SMAN Se-Kecamatan Koto Tangah Padang dilihat pada masing-masing indikator yaitu:

\subsection{Ruang Kelas}

Berdasarkan hasil penelitian dari masing-masing SMAN Se-Kecamatan Koto Tangah Padang terkait ruang kelas secara keseluruhan prasarana yang ada di SMAN 7, SMAN 8, SMAN 13 Padang telah sesuai dengan standar.

\subsection{Ruang Perpustakaan}

Berdasarkan hasil penelitian dari masing-masing SMAN Se-Kecamatan Koto Tangah Padang secara keseluruhan ruang perpustakaan di SMAN 7, SMAN 8, SMAN 13 Padang tergolong Sangat sesuai, baik dari segi fungsi perpustakaan, luas perpustakaan, serta letak dari perpustakaan.

3.3. Ruang Laboratorium Biologi

Masing-masing SMAN Se-Kecamatan Koto Tangah Padang terkait ruang laboratorium biologi di SMAN tersebut dengan hasil SMAN 7, SMAN 8, SMAN 13 Padang dikategorikan sangat sesuai, baik dari segi fungsi laboratorium biologi, luas dari laboratorium biologi, serta fasilitas pencahayaan.

3.4. Ruang Laboratorium Fisika

Masing-masing SMAN Se-Kecamatan Koto Tangah Padang terkait ruang laboratorium fisika di SMAN dengan hasil SMAN 7, SMAN 8, SMAN 13 Padang terkategori sangat sesuai, baik dari segi fungsi laboratorium fisika, luas dari laboratorium fisika, serta fasilitas pencahayaan.

3.5. Ruang Laboratorium Kimia

Masing-masing SMAN Se-Kecamatan Koto Tangah Padang terkait ruang laboratorium kimia di SMAN 7, SMAN 8, SMAN 13 Padang dikategorikan sangat sesuai, baik dari segi fungsi laboratorium kimia, luas dari laboratorium kimia, serta fasilitas pencahayaan.

3.6. Ruang Laboratorium Komputer

Masing-masing SMAN Se-Kecamatan Koto Tangah Padang terkait ruang laboratorium komputer di SMAN 7, SMAN 8, SMAN 13 Padang dengan hasil sangat sesuai, baik dari segi fungsi laboratorium komputer, luas masing-masing/peserta didik, luas dari laboratorium komputer.

3.7. Ruang Laboratorium Bahasa 
Masing-masing SMAN Se-Kecamatan Koto Tangah Padang terkait ruang laboratorium bahasa di SMAN 7, SMAN 8, SMAN 13 Padang tergolong tidak sesuai standar.

3.8. Ruang Pimpinan

Masing-masing SMAN Se-Kecamatan Koto Tangah Padang terkait ruang pimpinan di SMAN 7, SMAN 8, SMAN 13 Padang dikategorikan sangat sesuai standar, baik dari segi fungsi ruang pimpinan, luas dari ruang pimpinan, mudah diakses dan dapat dikunci.

3.9. Ruang Guru

Masing-masing SMAN Se-Kecamatan Koto Tangah Kota Padang terkait ruang guru di SMAN 7, SMAN 8 Padang sudah Sesuai, dan SMAN 13 Padang tergolong kurang sesuai dengan standar.

3.10. Ruang Tata Usaha

Masing-masing SMAN Se-Kecamatan Koto Tangah Padang terkait ruang TU di SMAN 7, SMAN 8, SMAN 13 Padang dengan hasil sangat sesuai, baik dari segi fungsi ruang TU, luas ruang TU/masingmasing petugas, mudah diakses dan dekat dengan ruang pimpinan.

3.11. Tempat Beribadah

Masing-masing SMAN Se-Kecamatan Koto Tangah Padang terkait tempat beribadah di SMAN 7, SMAN 8, SMAN 13 Padang tergolong sangat sesuai, baik dari segi fungsi tempat beribadah, kesesuaian terhadap kebutuhan, luas tempat beribadah.

3.12. Ruang Konseling

Masing-masing SMAN Se-Kecamatan Koto Tangah Padang terkait ruang konseling di SMAN 7, SMAN 8, SMAN 13 Padang terkategori sangat sesuai, baik dari segi fungsi ruang konseling, luas ruang konseling, suasana nyaman serta privasi peserta didik.

3.13. Ruang Unit Kesehatan Sekolah

Masing-masing SMAN Se-Kecamatan Koto Tangah Padang terkait ruang UKS di SMAN 7, SMAN 8, SMAN 13 Padang tergolong sangat sesuai, baik dari segi fungsi ruang UKS, luas ruang UKS.

3.14. Ruang Organisasi Kesiswaan

Masing-masing SMAN Se-Kecamatan Koto Tangah Padang terkait ruang organisasi kesiswaan di SMAN 13 Padang dengan hasil sangat sesuai dan SMAN 7, SMAN 8 Padang dengan hasil tidak sesuai standar.

3.15. Jamban/Toilet

Masing-masing SMAN Se-Kecamatan Koto Tangah Padang terkait jamban/toilet di SMAN 7, SMAN 8, SMAN 13 Padang telah sesuai standar.

3.16. Gudang

Masing-masing SMAN Se-Kecamatan Koto Tangah Padang terkait gudang di SMAN 13 Padang terkategori sangat sesuai, SMAN 8 Padang dikategorikan sesuai dan SMAN 7 Padang tergolong kurang sesuai standar.

3.17. Ruang Sirkulasi

Masing-masing SMAN Se-Kecamatan Koto Tangah Padang terkait ruang sirkulasi di SMAN 7, SMAN 8, SMAN 13 Padang telah sesuai standar.

3.18. Tempat Bermain/Berolahraga

Masing-masing SMAN Se-Kecamatan Koto Tangah Padang terkait tempat bermain/berolahraga di SMAN 13 Padang dikategorikan sangat sesuai dan SMAN 7, SMAN 8 Padang terkategori sesuai standar.

\title{
4. Kesimpulan
}

\author{
4.1. Ruang Kelas
}


Berdasarkan hasil penelitian dari masing-masing SMAN Se-Kecamatan Koto Tangah Padang dapat disimpulkan prasarana ruang kelas SMAN 7, SMAN 8, SMAN 13 Padang terkategori Sesuai dengan standar.

4.2. Ruang Perpustakaan

Berdasarkan hasil penelitian dari masing-masing SMAN Se-Kecamatan Koto Tangah Padang dapat disimpulkan prasarana ruang perpustakaan SMAN 7, SMAN 8, SMAN 13 Padang tergolong Sangat Sesuai dengan standar.

4.3. Ruang Laboratorium Biologi

Berdasarkan hasil penelitian dari masing-masing SMAN Se-Kecamatan Koto Tangah Padang dapat disimpulkan prasarana ruang laboratorium biologi SMAN 7, SMAN 8, SMAN 13 Padang dengan hasil Sangat Sesuai dengan standar.

4.4. Ruang Laboratorium Fisika

Berdasarkan hasil penelitian dari masing-masing SMAN Se-Kecamatan Koto Tangah Padang dapat disimpulkan prasarana ruang laboratorium fisika SMAN 7, SMAN 8, SMAN 13 Padang terkategorikan Sangat Sesuai dengan standar.

4.5. Ruang Laboratorium Kimia

Berdasarkan hasil penelitian dari masing-masing SMAN Se-Kecamatan Koto Tangah Padang dapat disimpulkan prasarana ruang laboratorium kimia SMAN 7, SMAN 8, SMAN 13 Padang tergolong Sangat Sesuai dengan standar.

4.6. Ruang Laboratorium Komputer

Berdasarkan hasil penelitian dari masing-masing SMAN Se-Kecamatan Koto Tangah Padang dapat disimpulkan prasarana ruang laboratorium komputer SMAN 7, SMAN 8, SMAN 13 Padang dengan hasil Sangat Sesuai dengan standar.

4.7. Ruang Laboratorium Bahasa

Berdasarkan hasil penelitian dari masing-masing SMAN Se-Kecamatan Koto Tangah Padang dapat disimpulkan prasarana ruang laboratorium bahasa SMAN 7, SMAN 8, SMAN 13 Padang dikategorikan Tidak Sesuai dengan standar.

4.8. Ruang Pimpinan

Berdasarkan hasil penelitian dari masing-masing SMAN Se-Kecamatan Koto Tangah Padang dapat disimpulkan prasarana ruang pimpinan SMAN 7, SMAN 8, SMAN 13 Padang terkategorikan Sangat Sesuai dengan standar.

4.9. Ruang Guru

Berdasarkan hasil penelitian dari masing-masing SMAN Se-Kecamatan Koto Tangah Padang dapat disimpulkan prasarana ruang guru SMAN 7, SMAN 8 Padang telah Sesuai dan SMAN 13 Padang digolongkan Kurang Sesuai dengan standar.

4.10. Ruang Tata Usaha

Berdasarkan hasil penelitian dari masing-masing SMAN Se-Kecamatan Koto Tangah Padang dapat disimpulkan prasarana ruang tata usaha SMAN 7, SMAN 8, SMAN 13 Padang dikategorikan Sangat Sesuai dengan standar.

4.11. Tempat Beribadah 
Berdasarkan hasil penelitian dari masing-masing SMAN Se-Kecamatan Koto Tangah Padang dapat disimpulkan prasarana tempat beribadah SMAN 7, SMAN 8, SMAN 13 Padang digolongkan Sangat Sesuai dengan standar.

4.12. Ruang Konseling

Berdasarkan hasil penelitian dari masing-masing SMAN Se-Kecamatan Koto Tangah Padang dapat disimpulkan prasarana ruang konseling SMAN 7, SMAN 8, SMAN 13 Padang terkategori Sangat Sesuai dengan standar.

4.13. Ruang UKS

Berdasarkan hasil penelitian dari masing-masing SMAN Se-Kecamatan Koto Tangah Padang dapat disimpulkan prasarana ruang SMAN 7, SMAN 8, SMAN 13 Padang dikategorikan Sangat Sesuai dengan standar.

4.14. Ruang Organisasi Kesiswaan

Berdasarkan hasil penelitian dari masing-masing SMAN Se-Kecamatan Koto Tangah Padang dapat disimpulkan prasarana ruang organisasi kesiswaan SMAN 13 Padang dengan hasil Sangat Sesuai dan SMAN 7, SMAN 8 Padang digolongkan Tidak Sesuai dengan standar.

4.15. Jamban/Toilet

Berdasarkan hasil penelitian dari masing-masing SMAN Se-Kecamatan Koto Tangah Padang dapat disimpulkan prasarana jamban/toilet SMAN 7, SMAN 8, SMAN 13 Padang telah Sesuai dengan standar prasarana.

4.16. Gudang

Berdasarkan hasil penelitian dari masing-masing SMAN Se-Kecamatan Koto Tangah Padang dapat disimpulkan prasarana gudang SMAN 13 Padang tergolong Sangat Sesuai, SMAN 8 Padang telah Sesuai dan SMAN 7 Padang dikategorikan Kurang Sesuai dengan standar.

4.17. Ruang Sirkulasi

Berdasarkan hasil penelitian dari masing-masing SMAN Se-Kecamatan Koto Tangah Padang dapat disimpulkan prasarana ruang sirkulasi SMAN 7, SMAN 8, SMAN 13 Padang telah Sesuai dengan standar.

4.18. Tempat Bermain/Berolahraga

Berdasarkan hasil penelitian dari masing-masing SMAN Se-Kecamatan Koto Tangah Padang dapat disimpulkan prasarana tempat bermain/berolahraga SMAN 13 Padang dengan hasil Sangat Sesuai dan SMAN 7, SMAN 8 Padang dikategorikan Sesuai dengan standar.

\section{Daftar Rujukan}

Amtu, O. (2011). Manajemen Pendidikan di Era Otonomi Daerah. Alfabeta.

Arikunto, S. (2010). Prosedur Penelitian: Suatu Pendekatan Praktik (Edisi Revisi). Rineka Cipta.

Darmadi, H. (2014). Metode Penelitian Pendidikan dan Sosial; Teori Konsep Dasar dan Implementasi. Alfabeta.

Indarwan, I. (1970). Implementasi Permendiknas No. 24 Tahun 2007 Tentang Standar Sarana dan Prasarana Pada MTs Al-Ihsaniyah dan MTs Aisyiyah 1 Palembang. Studia Manageria, 1(2), 149-164. https://doi.org/10.19109/studiamanageria.v1i2.4162

M.Arifin, B. \&. (2012). Manajemen Sarana dan Prasarana Sekolah. Ar-ruzz Media.

Permendiknas. (2007). Peraturan Menteri Pendidikan Nasional No 24 Tahun 2007. http://repositori.kemdikbud.go.id/18715/1/Permendiknas-No.-24-tahun-2007.pdf

UU RI, NO.20, 2003. (2003). Undang-Undang Republik Indonesia No 20 Tentang Sistem Pendidikan Nasional. 
Ridha Nabila 1, Syahril 2, Ahmad Sabandi 3, Yulianto Santoso 4 Implementasi Standar Prasarana di SMAN Se-Kecamatan Koto Tangah Padang

Jakarta: Direktorat Pendidikan Menengah Umum, 6. http://stpi-binainsanmulia.ac.id/wpcontent/uploads/2013/04/Lamp_2_UU20-2003-Sisdiknas.doc 